Article

\title{
Biotope impact on Fluctuating asymmetry manifestation in Ground beetles (Coleoptera, Carabidae)
}

Raisa A. Sukhodolskaya ${ }^{1,}{ }^{*}$, Anatoliy A. Saveliev ${ }^{2}$, Natalia I. Eremeeva ${ }^{3}$, Nadezhda L. Ukhova $^{4}$, Tatyana A. Gordienko", Rifgat R. Shagidullin'ㄹ, Iraida G. Vorobyova ${ }^{5}$, Igor A. Solodovnikov ${ }^{6}$, Anatoliy L. Anciferov ${ }^{7}$

${ }^{1}$ The Institute of Problems in Ecology and Mineral Wealth, Tatarstan Academy of Sciences, 28 Daurskaya str., Kazan 420087, Russian Federation; sukhodolskayaraisa@gmail.com; eiseniata@gmail.com;

shagidullin@mail.ru

${ }^{2}$ Kazan (Volga Region) Federal University, 18 Kremlevskaya str., Kazan 420018, Tatarstan, Russian

Federation; anatoly.saveliev.aka.saa@gmail.com

${ }^{3}$ Kemerovo State University, 6 Krasnaya str., Kemerovo 650000, Russian Federation; neremeeva@mail.ru

${ }^{4}$ Visimskiy Nature Reserve, 23 Stepan Razin srt., Kirovgrad 624144, Russian Federation; ukh08@yandex.ru

${ }^{5}$ Mariy State University, 57, Shkolnaya str., Yoshkar Ola 420039, Russian Federationvigir@mail.ru

${ }^{6}$ Educational establishment «Vitebsk State P.M. Masherov University», 33 Moskovskyi av., Vitebsk 210038,

Republic of Belarus; iasolodov@mail.ru

${ }^{7}$ Kostroma Museum-Reserve, 7 Mira av., Kostroma 156000, Russian Federation; ancifer.ost@yandex.ru

* Correspondence: sukhodolskayaraisa@gmail.com; Tel.: +79503152619

Abstract: In our study we used the data set on morphimetric traits in beetles species. It has been constantly replenishing for 20 years by the samples, received from different regions of Russia and abroad. In this case we have selected data on nine species for which the left and right sides had been measured and fluctuating asymmetry (FA) could be estimated. The samples were from 6 provinces of Russia and Belarus, which ranged in 3 degrees in latitude and 57 degrees in longitude and included more than 150 plots in different types of biotopes. FA was assessed according to the standard method in 5265 specimen in one dimensional trait and one - meristic. ANOVA showed that biotope, species and their interaction affected FA in both traits, that is different species reacted differently to biotope type. In uncommon biotopes (according to accepted in carabidology classification) FA was increased. In forest species the negative relationship between FA in dimensional and meristic traits in the range in biotopes was revealed. In those species only FA values were higher in males than in females. In generalist species FA varieв similarly in both sexes and in both traits being the highest in open biotopes. In eudomonant of arable lands biotopes Poecilus cupreus - the highest values of FA were recorded in the meadows, being about equal in all types of crops.

Keywords: fluctuating asymmetry; ground beetles; morphometric variation; biotope impact; species*biotope interaction; negative relationship between dimensional and meristic traits. 
2 of 16

\section{Introduction}

The body size of an animal is one of the most widely studied traits in biology because it has a potent impact on various aspects of the life-history of a given organism, from physiology to ecology and evolution [1]. In a long-term macroevolutionary context, body size may have serious effects on speciation and extinction processes mediated by its effects on population density, resource exploitation, generation time, etc. [2-ㅡ] . On the short-term ecological and microevolutionary timescale, body size is a crucial feature affecting individual fitness.

That is why body size variation is frequently used in the studies concerning the level of adaptation of certain species. Apparently it is seen in the researches when fluctuating asymmetry (FA) is taken into account. The latter is the admitted indicator of development stress in the certain environmental conditions. In this aspect the most valuable studies were done in insects with holometabolism, because their imagoes do not change body size and its proportions during the remaining ontogenesis [4-ㅗ]. Ground beetles are no exception. Being the recognized bioindicators [음] , they are widely used in bioindicative practice. Effects of urbanization and sampling region on FA manifestation were revealed, besides FA in carabids turned to be species and sex biased [10].

The aim of this study was to research biotope peculiarities impact on FA in ground beetles, emphasizing biotope vegetation. Ground beetles are characterized by biotope confinement and in

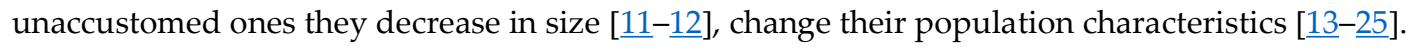

We hypothesized that: (i) factors "biotope and species" interact when affecting FA;

(ii) FA level is biotope biased; (iii) in uncommon biotopes FA level is increased; (iv) FA in males is higher than in females.

\section{Materials and Methods}

Study organisms. We analyzed FA in nine carabid species: Carabus aeruginosus (Fischer von Waldheim, 1823), Carabus (Carabus) granulatus Linnaeus 1758, Carabus (Tachypus) cancellatus Illiger 1798, Carabu arvensis Hbst. 1784, Pterostichus melanarius Illiger 1798, Pterostichus niger Schaller 1783, Pterostichus oblongopunctatus Fabricius, 1787, Poecilus cupreus Linnaeus 1758, Pseudoophonus rufipes Dejean, 1828. All of them (except C. aeruginosus) are widespread in Paleartic, generalists, zoophagous and mesophilous. C. aeruginosus is a Siberian species.

Collection sites and sampling methods. In our investigations we used our data set of morphometric measurements in ground beetles. It was funded in 1996 and has been complementing to date by new information: in the scientific contracts frames our colleagues - carabidologists have been sending the beetles to our laboratory, where we have been measuring them for several morphological traits. At present this data set includes more than 60000 rows and this data is used for different purposes. For the purposes of this study we have extracted the data, including the left and right sides measurements of beetles. So we formed the data set of our further analysis including data in seven species of ground beetles (Table 1). They were sampled in different years and in different provinces of Russia and Belarus (Fig. 1). But we compiled all data taking into account only two variables species and biotope. The others were ignored, because factor "Province" impact had been studied earlier [10]. Sampling year impact can be ignored also because sampling period in each province is no less than three years and the possible fluctuations in FA year by year neutralize each other. 
Table 1. Sample size when estimating FA in studied species of carabids.

\begin{tabular}{|c|c|c|c|c|c|c|c|c|c|c|}
\hline & & 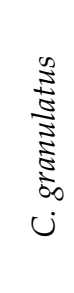 & 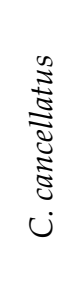 & 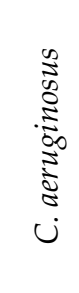 & $\begin{array}{l}\frac{w}{w} \\
\frac{1}{2} \\
\frac{2}{2} \\
ن\end{array}$ & 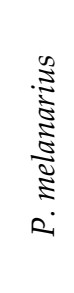 & $\begin{array}{l}\grave{\Xi} \\
\stackrel{.0}{\Xi} \\
0\end{array}$ & 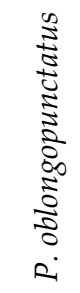 & 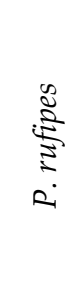 & $\begin{array}{l}\text { a } \\
\frac{3}{3} \\
0 \\
0 \\
0\end{array}$ \\
\hline \multirow{2}{*}{ Linden } & $\mathrm{f}$ & 30 & 57 & - & - & 67 & - & - & 114 & - \\
\hline & $\mathrm{m}$ & 25 & 73 & - & - & 192 & - & - & 167 & - \\
\hline \multirow{2}{*}{ Pine } & $\mathrm{f}$ & 8 & 7 & 49 & 9 & 279 & 44 & 157 & 22 & - \\
\hline & $\mathrm{m}$ & 0 & 7 & 34 & 14 & 128 & 17 & 17 & 33 & - \\
\hline \multirow{2}{*}{ Meadow } & $\mathrm{f}$ & 26 & 0 & 218 & - & 94 & - & 31 & - & 41 \\
\hline & $\mathrm{m}$ & 122 & 40 & 159 & - & 111 & - & 7 & - & 51 \\
\hline \multirow{2}{*}{ Birch } & $\mathrm{f}$ & 4 & 16 & - & - & 0 & - & - & - & - \\
\hline & $\mathrm{m}$ & 4 & 35 & - & - & 3 & - & - & - & - \\
\hline \multirow{2}{*}{ Lawn } & $\mathrm{f}$ & 56 & 11 & 33 & - & - & - & 32 & - & - \\
\hline & $\mathrm{m}$ & 8 & 21 & 30 & - & - & - & 90 & - & - \\
\hline \multirow{2}{*}{ Spring wheat } & $\mathrm{f}$ & - & 22 & - & - & - & - & - & - & 124 \\
\hline & $\mathrm{m}$ & - & 25 & - & - & - & - & - & - & 74 \\
\hline \multirow{2}{*}{ Winter wheat } & $\mathrm{f}$ & - & - & - & - & - & - & - & - & 188 \\
\hline & $\mathrm{m}$ & - & - & - & - & - & - & - & - & 207 \\
\hline \multirow{2}{*}{ Raspberry } & $\mathrm{f}$ & - & 41 & - & - & - & - & - & 89 & - \\
\hline & $\mathrm{m}$ & - & 23 & - & - & - & - & - & 59 & - \\
\hline \multirow{2}{*}{ Schrubs } & $\mathrm{f}$ & 5 & - & - & - & - & - & - & - & - \\
\hline & $\mathrm{m}$ & 9 & - & - & - & - & - & - & - & - \\
\hline \multirow{2}{*}{ Swamp } & $\mathrm{f}$ & 0 & - & - & - & - & - & - & - & - \\
\hline & $\mathrm{m}$ & 16 & - & - & - & - & - & - & - & - \\
\hline \multirow{2}{*}{ Barley } & $\mathrm{f}$ & - & - & - & - & - & - & - & - & 166 \\
\hline & $\mathrm{m}$ & - & - & - & - & - & - & - & - & 124 \\
\hline \multirow{2}{*}{ Maize } & $\mathrm{f}$ & - & - & - & - & - & - & - & - & 41 \\
\hline & $\mathrm{m}$ & - & - & - & - & - & - & - & - & 30 \\
\hline \multirow{2}{*}{ Lucerne } & $\mathrm{f}$ & - & - & - & - & - & - & - & - & 36 \\
\hline & $\mathrm{m}$ & - & - & - & - & - & - & - & - & 64 \\
\hline \multirow{2}{*}{ Oats } & $\mathrm{f}$ & - & - & - & - & - & - & - & - & 229 \\
\hline & $\mathrm{m}$ & - & - & - & - & - & - & - & - & 117 \\
\hline \multirow{2}{*}{ Pea } & $\mathrm{f}$ & - & - & - & - & - & - & - & - & 105 \\
\hline & $\mathrm{m}$ & - & - & - & - & - & - & - & - & 69 \\
\hline \multirow{2}{*}{ Carrot } & $\mathrm{f}$ & - & - & - & - & - & - & - & - & 48 \\
\hline & $\mathrm{m}$ & - & - & - & - & - & - & - & - & 29 \\
\hline
\end{tabular}




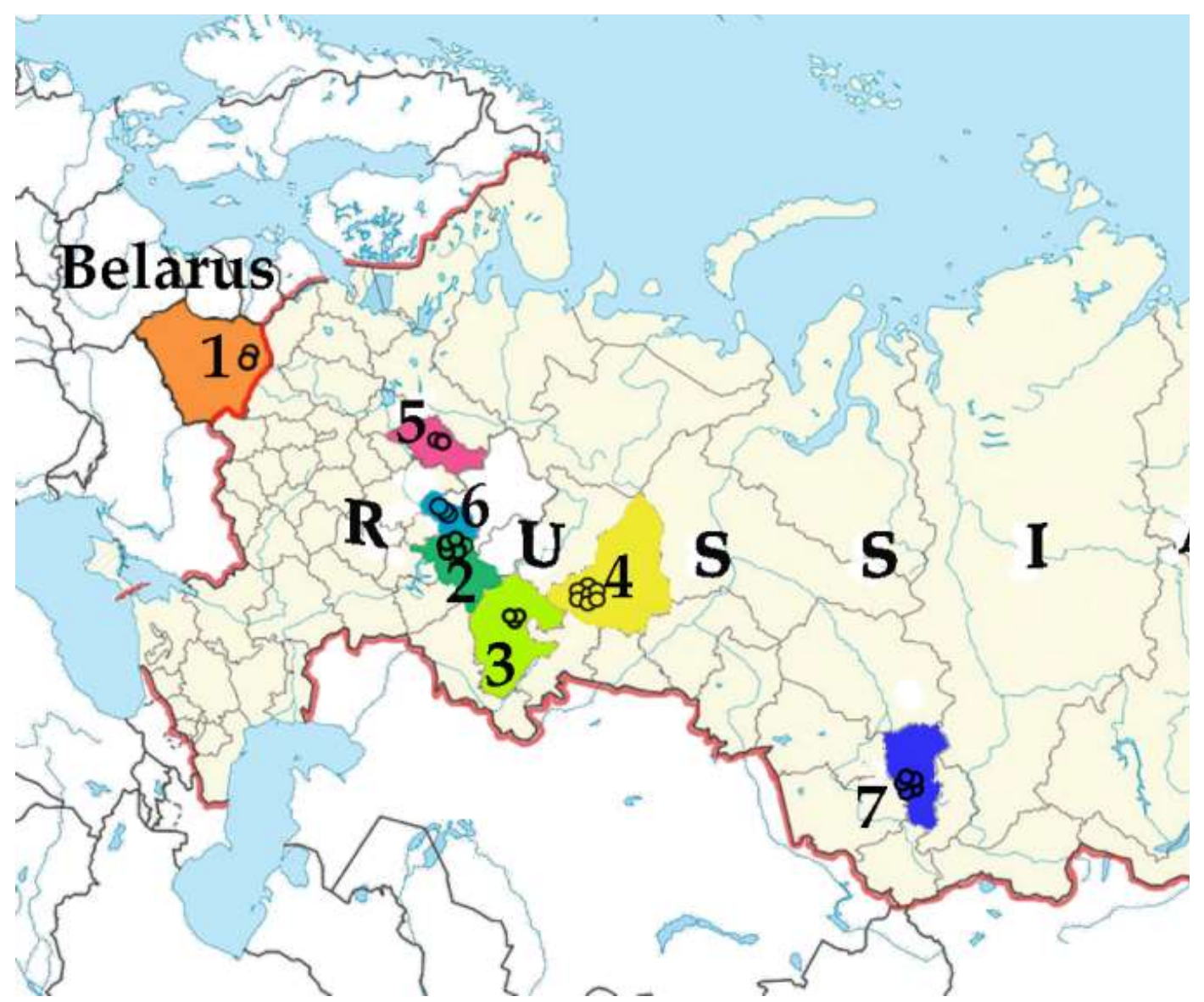

Figure 1. Provinces of Russia and Belarus, where the beetles were received from: 1 - Belarus Republic, 2 -Tatarstan Republic, 3 - Bashkortostan Republic, 4 - Sverdlovsk Province, 5 - Kostroma Province, 6 - Mariy El Republic, 7 - Kemerovo province.

So studied beetles were sampled by the unified method (pitfall traps), all photos were taken by one person using the same method. Morphometric data was collected from images taken by Nikon D5100 camera with custom opaque light disperser and a box with opaque reflective surface. Measurements were made using program, designated specifically for the given method of measurement and utilized distance between manually pointed out elements of photos' arrays as terminal point of measurements and fiducial scale, using the last to bind real scale to array output data (Fig. 2). For each of specimens we measured the right and left elytra width (further dimensional trait). Besides dimensional trait we analyzed meristic traits and counted: the number of tubercles in the first line near medial ridge of the scutellum (in C. granulatus, C. cancellatus), the number of spots on the left and right elytra (in P. oblongopunctatus), the number of furrows on the left and right elytra (in P. melanarius, Poec. cupreus). C. aeruginosus and C. arvensis have no such meristic traits, so data on it is absent in certain figures in Results and in the tables - in Supplement.

Statistical analysis. For each specimen we calculated fluctuating asymmetry (FA) index (FA $=\mid R$ $-\mathrm{LI} /(\mathrm{R}+\mathrm{L}) / 2$, where $\mathrm{R}$ - the value of trait at the right elytra, while $\mathrm{L}$ denotes the value of trait at the left elytra.

We analyzed measurements from Poec. cupreus separately, because it is arable lands species and its biotopes differed drastically from all the others, where the other species were sampled. 


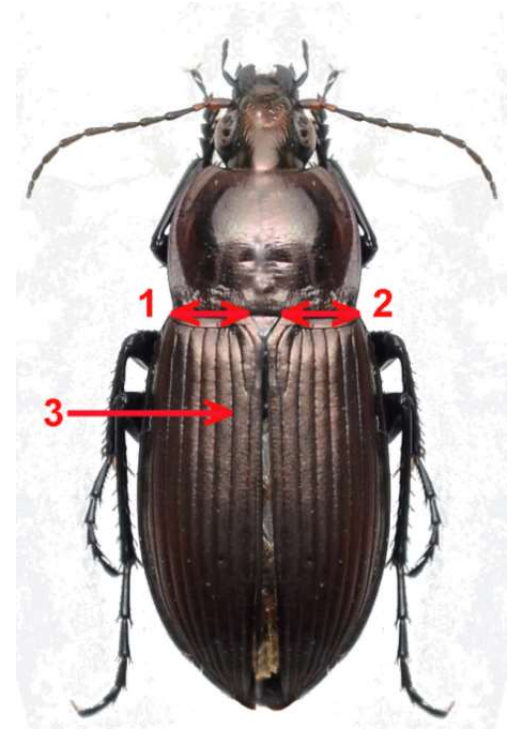

Figure 2. The scheme of dimensional and meristic traits estimation: 1 - the width of the left elytra, 2 - the width of the right elytra, 3 - furrows on Poec. cupreus elytra (as illustration).

We used LM to recognize what kind of biotope affected FA in ground beetles and how it is connected with species specificity and sex:

$\operatorname{lm}\left(\right.$ formula $=$ FA_.dimensional $\sim$ fBiotope ${ }^{*}$ fSpecies + fBiotope $*$

FA_.dimensional $\sim$ fBiotope ${ }^{*}$ fSpecies + fBiotope ${ }^{*}$ fSex

$\operatorname{lm}($ formula $=$ FA_dimensional $\sim$ fBiotope $+\mathrm{fSpecies}+\mathrm{fSex}$, data $=\mathrm{p})$

FA_dimensional $\sim$ fBiotope + fSpecies + fSex

$\operatorname{lm}\left(\right.$ formula $=$ FA_meristic $\sim$ fBiotope ${ }^{*}$ fSpecies + fBiotope ${ }^{*} \mathrm{fSex}$, data $\left.=\mathrm{p}\right)$

FA_meristic $\sim$ fBiotope ${ }^{*}$ fSpecies + fBiotope ${ }^{*}$ fSex

$\operatorname{lm}($ formula $=$ FA_meristic $\sim$ fBiotope + fSpecies + fSex, data $=p)$

FA_meristic $\sim$ fBiotope + fSpecies + fSex

\section{Results}

FA in dimensional trait appeared to be affected by species*biotope, but not biotope* sex interactions (Table 2, S1). In other words, FA level in the beetles from the same type of biotope was depended from species, but it is not dependent by those beetles sex. This is especially clear for $C$. granulatus, C. cancellatus and P. melanarius (Table S1).

Table 2. ANOVA results when studying species*biotope and biotope*sex interactions on FA in dimensional trait in studied species of carabids.

FA_dimensional $\sim$ fBiotope ${ }^{*}$ fSpecies + fBiotope ${ }^{*}$ fSex

\begin{tabular}{cccccccc}
\hline Source & Df & Sum of Sq & RSS & AIC & Fvalue & $\operatorname{Pr}(>$ F) \\
\hline <none> & & & 6.8809 & -15950 & & & \\
fBiotope:fSpecies & 10 & 0.38842 & 7.2694 & -15823 & 14.9590 & $<2 \mathrm{e}-16$ & $* * *$ \\
fBiotope:fSex & 7 & 0.03617 & 6.9171 & -15950 & 1.9899 & 0.05288 &. \\
\hline
\end{tabular}

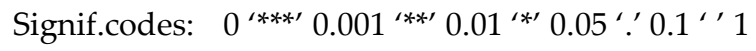


This conclusion became more pronounced when modeling different variables impact against the background of others (Table 3): biotope type and species affected significantly FA in studied samples. This was again especially clear for C.granulatus, C. cancellatus and all types biotopes except shrubs and swamp (Table S2).

Table 3. ANOVA results when studying biotope, species and sex on FA in dimensional trait in studied species of carabids.FA_dimensional $\sim$ fBiotope + fSpecies + fSex

\begin{tabular}{|c|c|c|c|c|c|c|c|}
\hline Source & Df & Sum of Sq & RSS & AIC & Fvalue & $\operatorname{Pr}(>F)$ & \\
\hline$<$ none $>$ & & & 7.3023 & -15825 & & & \\
\hline fBiotope & 8 & 1.24616 & 8.5485 & -15418 & 56.8914 & $<2 \mathrm{e}-16$ & $* * *$ \\
\hline fSpecies & 8 & 0.80809 & 8.1104 & -15559 & 36.8917 & $<2 \mathrm{e}-16$ & $* * *$ \\
\hline fSex & 1 & 0.00645 & 7.3088 & -15825 & 2.3572 & 0.1248 & \\
\hline
\end{tabular}

FA in meristic traits was affected by species*biotope, but not biotope* sex interactions, similar to dimensional trait, though with lower significance (Table 4, S3). Though all species included to biotope* ${ }^{*}$ species interaction and Intercept was significant, the only one case of such interaction was significant (Table S3) and there were no interactions of biotope and sex. So FA in meristic trait was practically independent of biotope type where the carabid species dwelled.

Table 4. ANOVA results when studying species*biotope and biotope*sex interactions on FA in meristic trait in studied species of carabids.FA_meristic $\sim$ fBiotope ${ }^{*}$ fSpecies + fBiotope ${ }^{*}$ fSex

\begin{tabular}{|c|c|c|c|c|c|c|c|}
\hline Source & Df & Sum of Sq & RSS & AIC & Fvalue & $\operatorname{Pr}(>\mathrm{F})$ & \\
\hline$<$ none $>$ & & & 5.8319 & -16380 & & & \\
\hline fBiotope:fSpecies & 10 & 0.045564 & 5.8775 & -16380 & 2.0688 & 0.02376 & * \\
\hline fBiotope:fSex & 7 & 0.010954 & 5.8428 & -16389 & 0.7106 & 0.66314 & \\
\hline
\end{tabular}

That conclusion was confirmed by the next analysis (Table 5, S4): FA in meristic trait was species-specific in all studied species.

Table 5. ANOVA results when studying biotope, species and sex on FA in meristic trait in studied species of carabids.FA_meristic $\sim$ fBiotope + fSpecies + fSex

\begin{tabular}{cccccccc}
\hline Source & Df & Sum of Sq & RSS & AIC & Fvalue & $\operatorname{Pr}(>$ F $)$ & \\
\hline$<$ none $>$ & & & 5.8941 & -16386 & & & \\
fBiotope & 8 & 0.02657 & 5.9207 & -16390 & 1.5014 & 0.1513 & \\
fSpecies & 8 & 0.83126 & 6.7254 & -16048 & 46.9817 & $<2 \mathrm{e}-16$ & $* * *$ \\
fSex & 1 & 0.00082 & 5.8949 & -16388 & 0.3707 & 0.5427 & \\
\hline
\end{tabular}

Similarly we analyzed data set in Poec. cupreus. FA in dimensional trait was significantly affected by biotope, but not biotope* sex interactions, sex by itself did not affect FA also (Tables 6,7, S5,6). In meristic trait, on the contrary, FA was significantly affected by biotope, biotope* sex interaction, but not by the sex by itself (Tables 8,9, S7,8). 
Table 6. ANOVA results when studying biotope* sex interactions on FA in dimensional trait in Poec. cupreus.FA_dimensional fBiotope * fSex

\begin{tabular}{ccccccc}
\hline Source & Df & Sum of Sq & RSS & AIC & Fvalue & $\operatorname{Pr}(>$ F $)$ \\
\hline $\begin{array}{c}\text { <none }> \\
\text { fBiotope:fSex }\end{array}$ & 8 & 0.0038391 & 0.81759 & -13340 & 1.0173 & 0.4206 \\
\hline
\end{tabular}

Table 7. ANOVA results when studying biotope and sex on FA in dimensional trait in Poec.

cupreus.FA_dimensional $\sim$ fBiotope + fSex

\begin{tabular}{cccccccc}
\hline Source & Df & Sum of Sq & RSS & AIC & Fvalue & $\operatorname{Pr}(>\mathbf{F})$ & \\
\hline <none & & & 0.81759 & -13340 & & & \\
fBiotope & 8 & 0.089004 & 0.90659 & -13176 & 23.582 & $<2 \mathrm{e}-16$ & $* * *$ \\
fSex & 1 & 0.000327 & 0.81792 & -13341 & 0.694 & 0.4049 & \\
\hline Signif & $0^{* * * * \prime}$ & $001^{* * \prime} 0.01^{\prime * \prime} 0.05^{\prime \prime}, 01^{\prime \prime} 1$ & & &
\end{tabular}

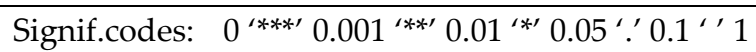

Table 8. ANOVA results when studying biotope*sex interactions on FA in dimensional trait

in Poec. cupreus.FA_meristic $\sim$ fBiotope ${ }^{*}$ fSex

\begin{tabular}{|c|c|c|c|c|c|c|c|}
\hline Source & Df & Sum of Sq & RSS & AIC & Fvalue & $\operatorname{Pr}(>\mathrm{F})$ & \\
\hline$<$ none $>$ & & & 0.69716 & -13601 & & & \\
\hline fBiotope:fSex & 8 & 0.010471 & 0.70763 & -13591 & 3.2387 & 0.001154 & $* *$ \\
\hline
\end{tabular}

Table 9. ANOVA results when studying biotope and sex on FA in dimensional trait in Poec. cupreus.

$$
\text { FA_meristic } \sim \text { fBiotope }+ \text { fSex }
$$

\begin{tabular}{cccccccc}
\hline Source & Df & Sum of Sq & RSS & AIC & Fvalue & $\operatorname{Pr}(>\mathbf{F})$ & \\
\hline $\begin{array}{c}\text { <none }> \\
\text { fBiotope }\end{array}$ & 8 & 0.095860 & 0.80349 & -13386 & 29.3455 & $<2 \mathrm{e}-16$ & $* * *$ \\
fSex & 1 & 0.000472 & 0.70810 & -13592 & 1.1563 & 0.2824 & \\
\hline
\end{tabular}

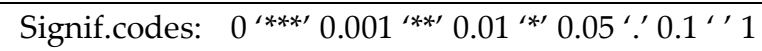

The actual values of FA in different species and in different biotopes are presented at the following series of figures.

In C. granulatus $\mathrm{FA}$ in dimensional trait in females fitted in the row: linden=shrubs=birch $<$ meadow $<$ lawn, that is the highest FA level was in the lawn. In males already FA was roughly speaking similar in all biotopes (Fig. 3). If we exclude some biotopes from the figure due small samples in them (i.e. pine, birch, shrubs, swamp), then we can obtain the following picture of dimensional trait FA variation in different biotopes: linden<meadow<lawn. Noteworthy that for meristic trait in females relation was the opposite: lawn=meadow<linden. So for C. granulatus the opposite trend occurred: FA in dimensional trait was the highest in the forest biotope, and in meristic trait - in the open one.

In $C$. cancellatus $\mathrm{FA}$ in dimensional trait in females fitted in the row: spring wheat $<$ linden<birch<lawn<raspberry (biotope "pine" we counted out because of the small sample). In males the tendencies of FA variation were similar (Fig. 4).

In meristic trait (similar to the previous species- C. granulatus) the opposite trend of FA in dimensional and meristic traits: the highest FA in C. cancellatus dimensional trait was observed in open habitats (lawn), and in meristic trait - in forest one (linden). 
8 of 16

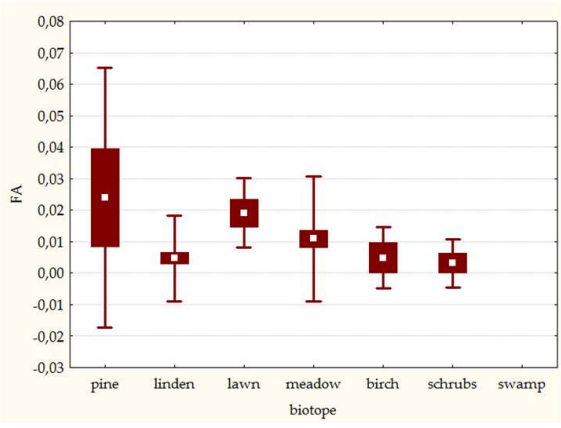

a

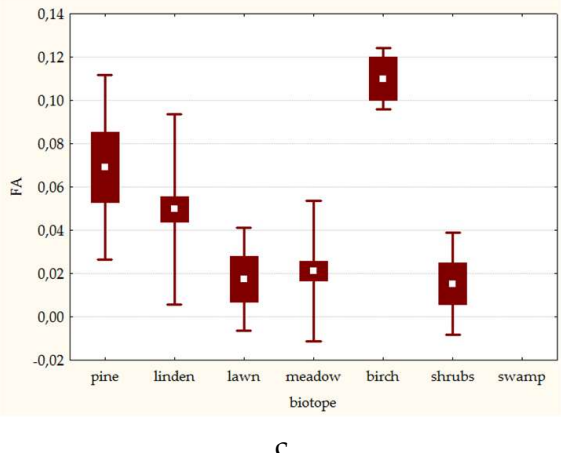

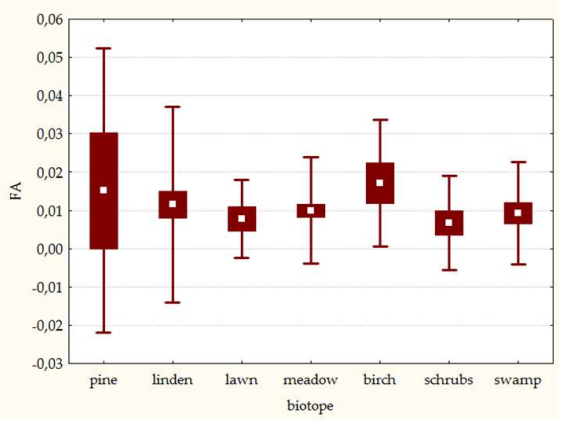

b

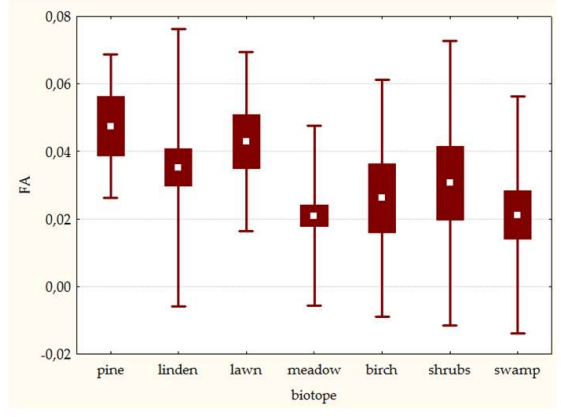

d

Figure. 3.FA in C. granulatus in different biotopes. Mean value (square), mean \pm SE (boxes), mean \pm SD (whiskers); a, c-females; b, d-males; a, b, - dimensional trait, c, d- meristic trait.

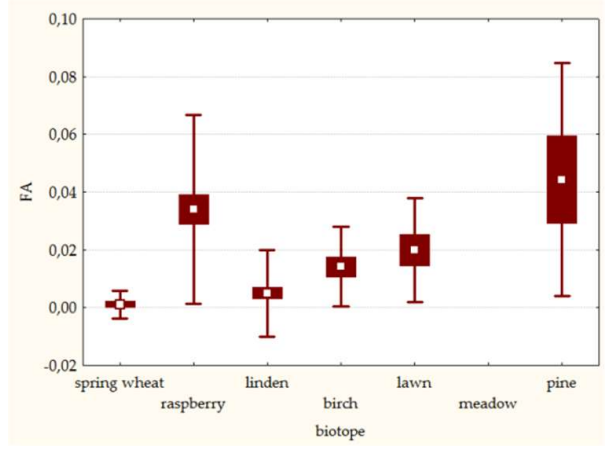

a

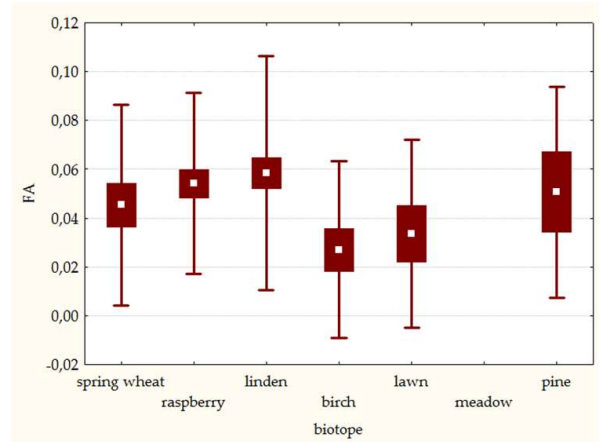

C

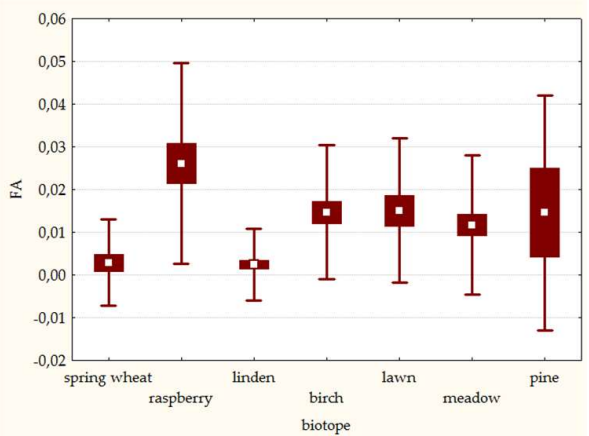

b

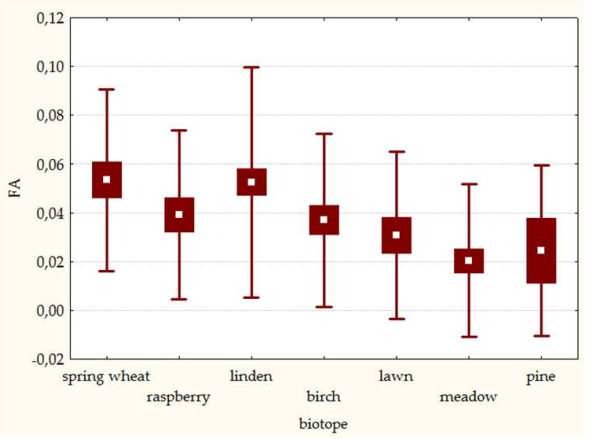

d

Figure 4. FA in C. cancellatus in different biotopes. Mean value (square), mean $\pm S E$ (boxes), mean $\pm S D$ (whiskers); a, c-females; b, d-males; a, b, - dimensional trait, c, d-meristic trait. 
C. aeruginosus did not show any differences in FA values in different biotopes neither in females nor in males (Fig. 5).

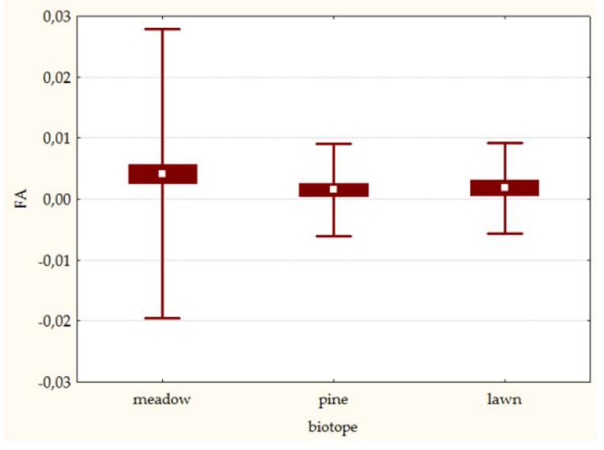

a

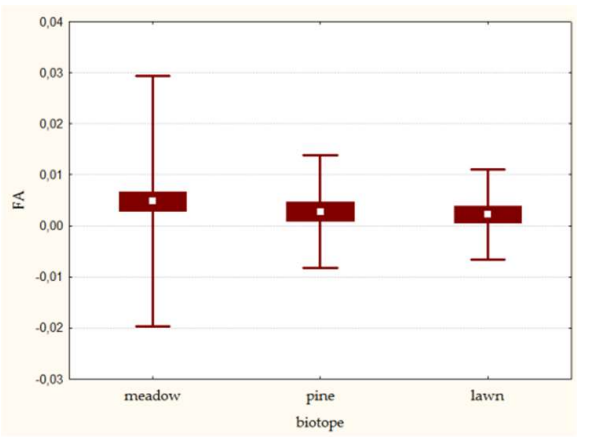

b

Figure 5. FA of dimensional trait in C. aeruginosus in different biotopes. Mean value (square), mean \pm SE (boxes), mean \pm SD (whiskers); $\mathrm{a}$ - females; $\mathrm{b}$ - males.

In $C$. arvensis in a single type of biotope FA was significantly higher in males than in females in studied traits (Fig. 6), but in P. niger in the same biotope FA was similar in males and females (Fig. 7).

In P. melanarius FA in both traits and in females and males as well fitted in the row: birch $<$ pine $<$ linden $<$ meadow, thus, FA being the highest in open biotope (Fig. 8).

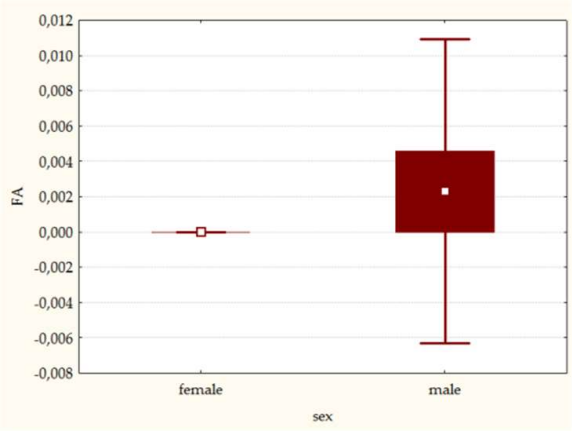

a

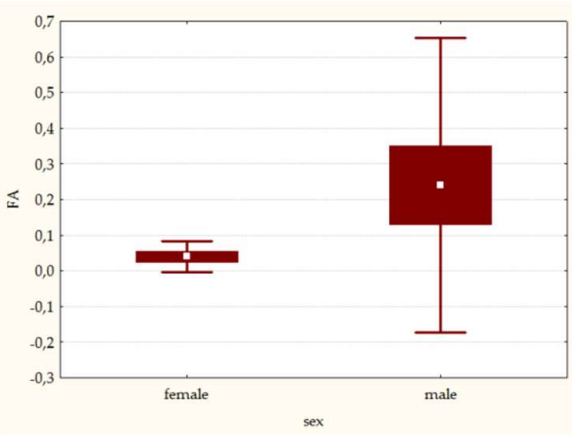

b

Figure 6. FA of dimensional trait in C. arvensis in different biotopes. Mean value (square), mean $\pm \mathrm{SE}$ (boxes), mean $\pm \mathrm{SD}$ (whiskers); $\mathrm{a}$ - females; $\mathrm{b}$ - males.

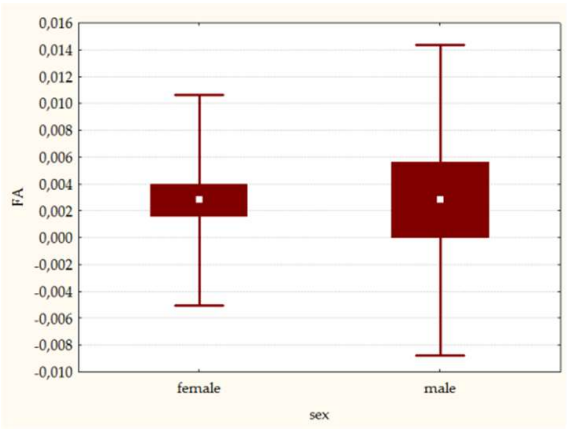

a

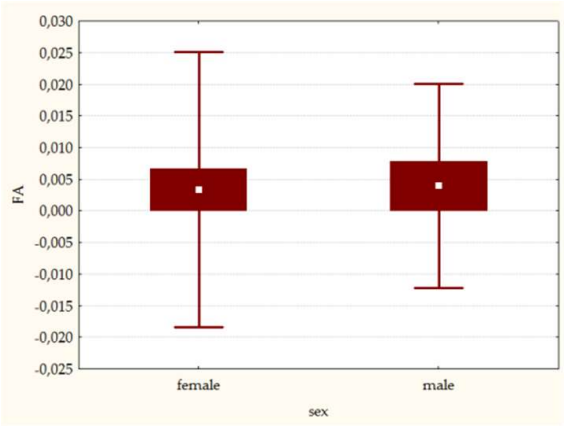

b

Figure 7. FA in P. niger in different biotopes. Mean value (square), mean \pm SE (boxes), mean \pm SD (whiskers); a dimensional trait; $b$ - meristic trait. 


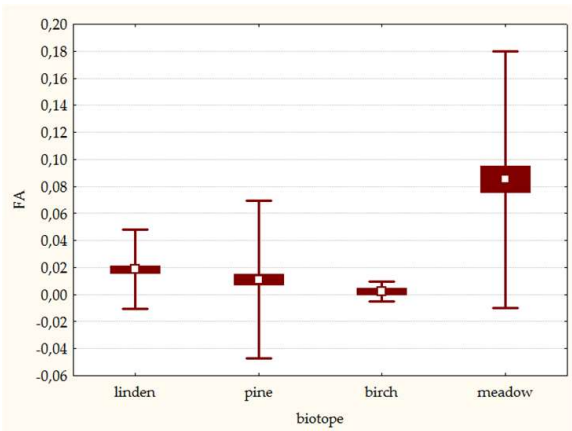

a

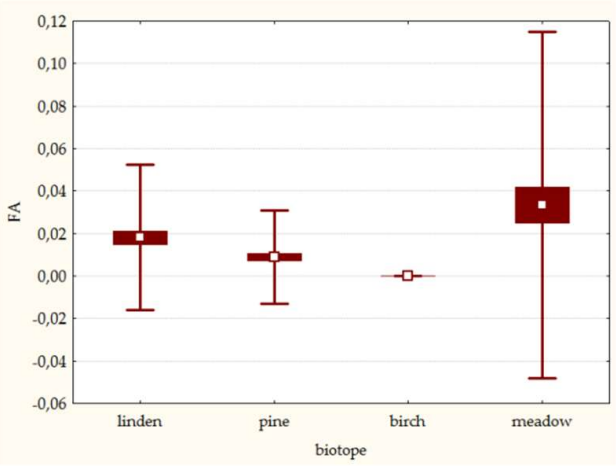

C

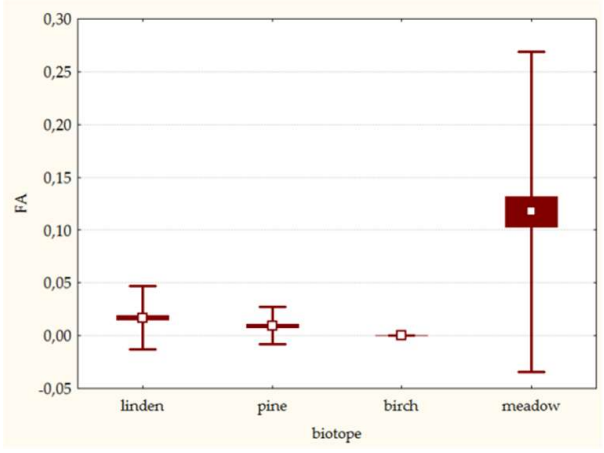

$\mathrm{b}$

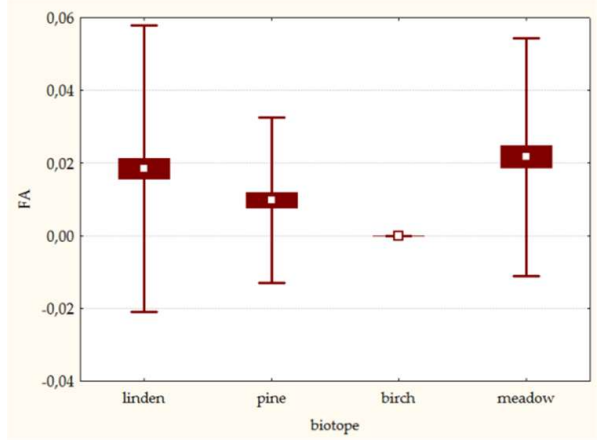

d

Figure 8. FA in P. melanarius in different biotopes. Mean value (square), mean \pm SE (boxes), mean \pm SD (whiskers); a, c-females; b, d-males; a, b, - dimensional trait, c, d- meristic trait.

The opposite trends in dimensional trait were observed in P. oblongopunctatus, the highest value of FA being in open biotope (lawn) and the lowest - in the forest (pine) (Fig. 9). But in meristic trait FA values were the highest exactly in forest biotopes (pine, linden), that is the opposite trends in relation to two studied traits were revealed. Those trends were similar to observed in C. granulatus and C. cancellatus.

In Ps. rufipes FA in both traits and in females and males as well fitted in the row: raspberry<linden<pine (Fig. 10). By the similarity of the variability of asymmetry for both traits it is similar with $P$. melanarius.

As for the last species studied - Poec. cupreus - the highest value of FA in it was in meadow. It was true both for females and males by dimensional trait and meristic trait (Fig. 11 - 14).

\section{Discussion}

In previous paper [10] significant species, anthropogene, sex and locality effects on FA manifestation were shown. In this article similar biotope effect was revealed. Especially important is that that effect interacted with species level. In other words, FA realized differently in different species in the same biotope. This conclusion has the direct relation to bioindication where FA is used. That is to say, for instance, if we estimate FA in the C. cancellatus in the city biotopes (these are lawns and meadows as a rule) and in natural ones (linden, for instance), the high level of FA in the city populations will be determined exactly by biotope peculiarities, but not by factor "the city". And the conclusions about negative environment in the city will be wrong. 


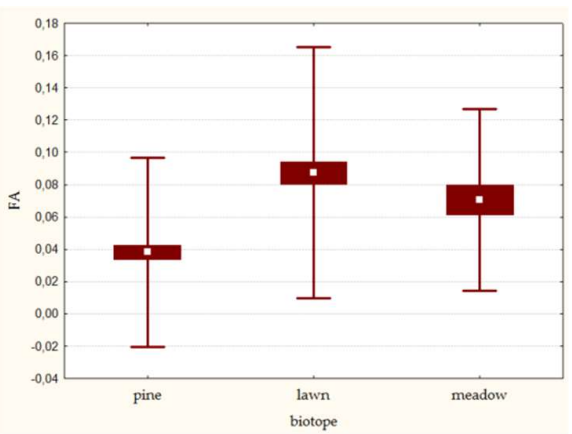

a

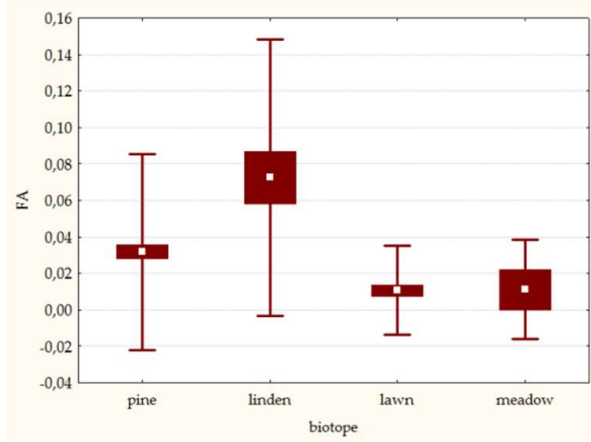

c

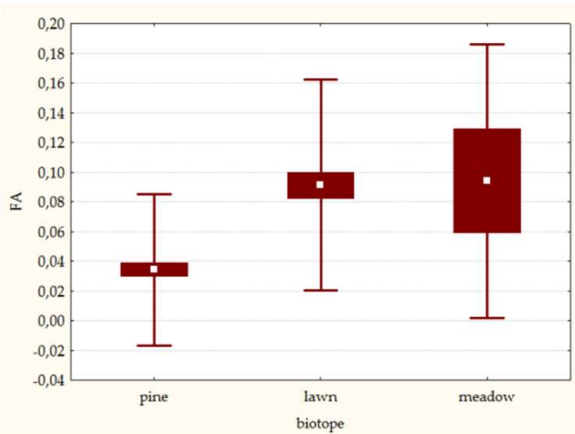

b

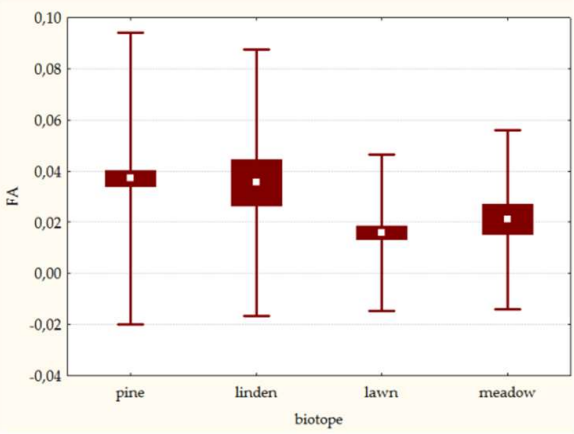

d

Figure 9. FA in P. oblongopunctatusin different biotopes. Mean value (square), mean \pm SE (boxes), mean \pm SD (whiskers); a, c-females; b, d-males; a, b, - dimensional trait, c, d-meristic trait.

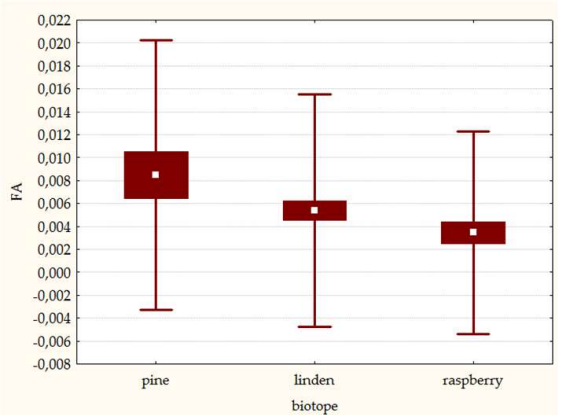

a

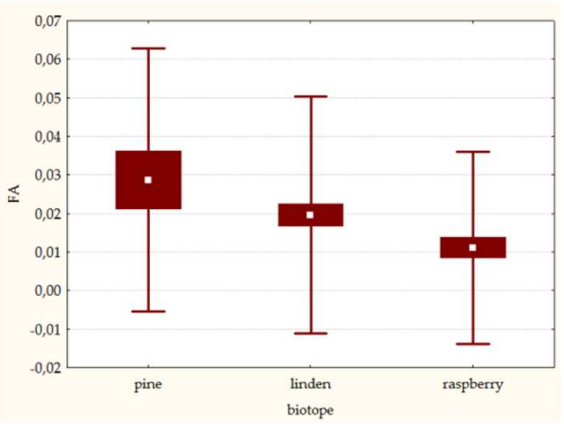

c

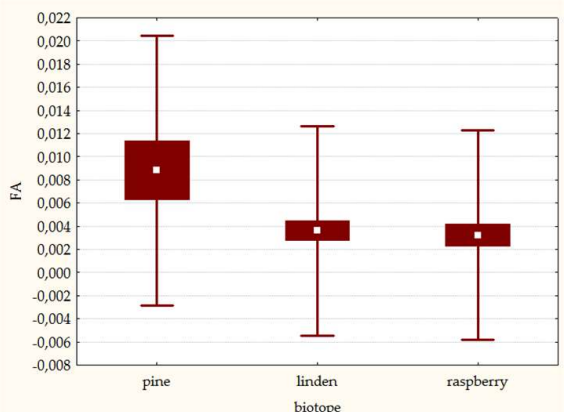

b

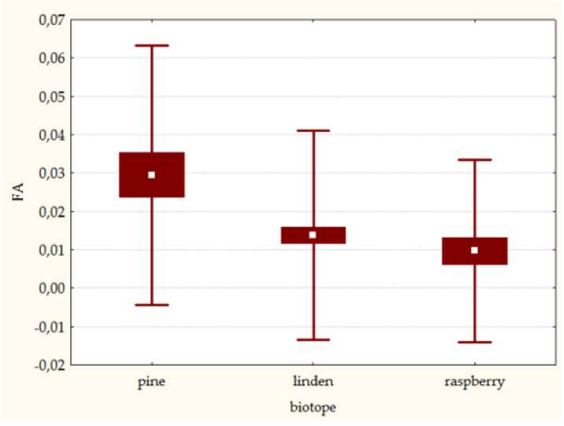

d

Figure 10. FA in Ps. rifipes in different biotopes. Mean value (square), mean $\pm \mathrm{SE}$ (boxes), mean $\pm \mathrm{SD}$ (whiskers); a, c - females; b, d- males; a, b, - dimensional trait, c, d- meristic trait. 


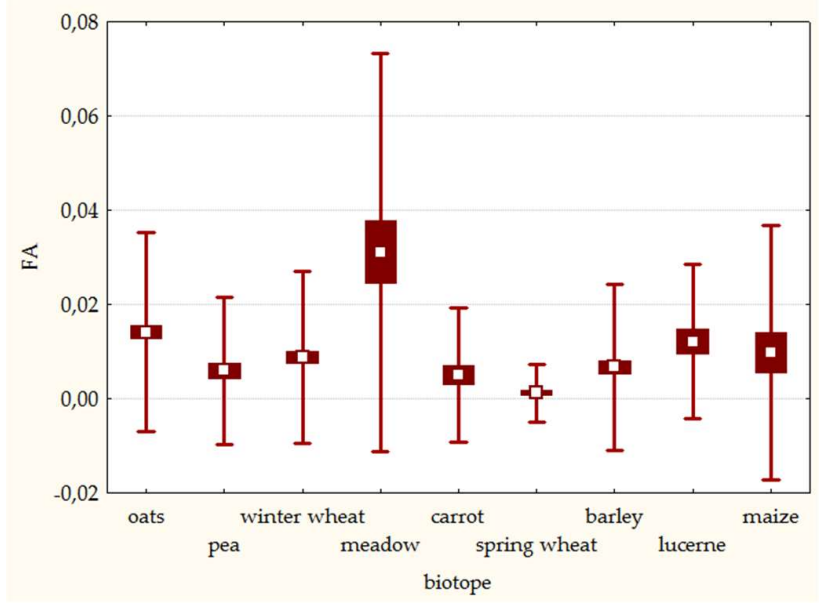

Figure 11. FA in females dimensional trait in Poec. cupreus in different biotopes. Mean value (square), mean \pm SE (boxes), mean \pm SD (whiskers).

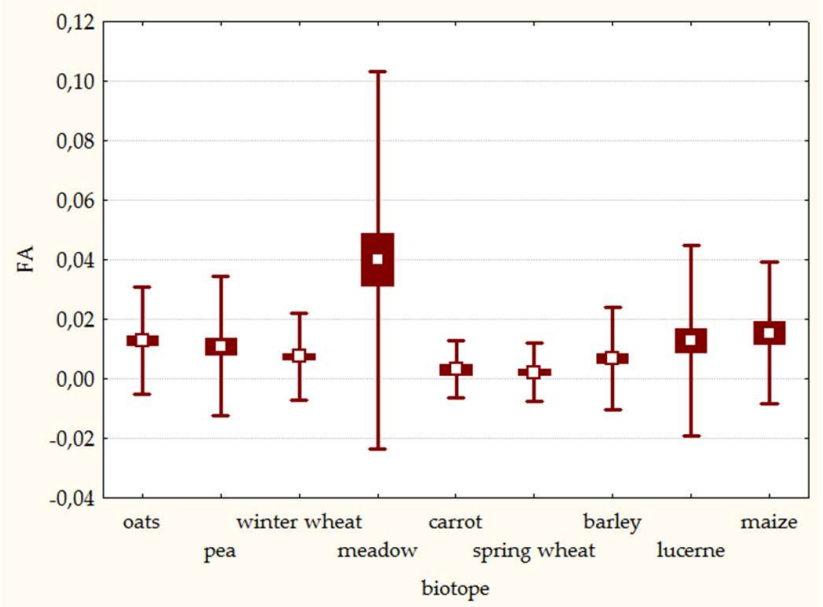

Figure 12.FA in males dimensional trait in Poec. cupreus in different biotopes. Mean value (square), mean \pm SE (boxes), mean $\pm \mathrm{SD}$ (whiskers).

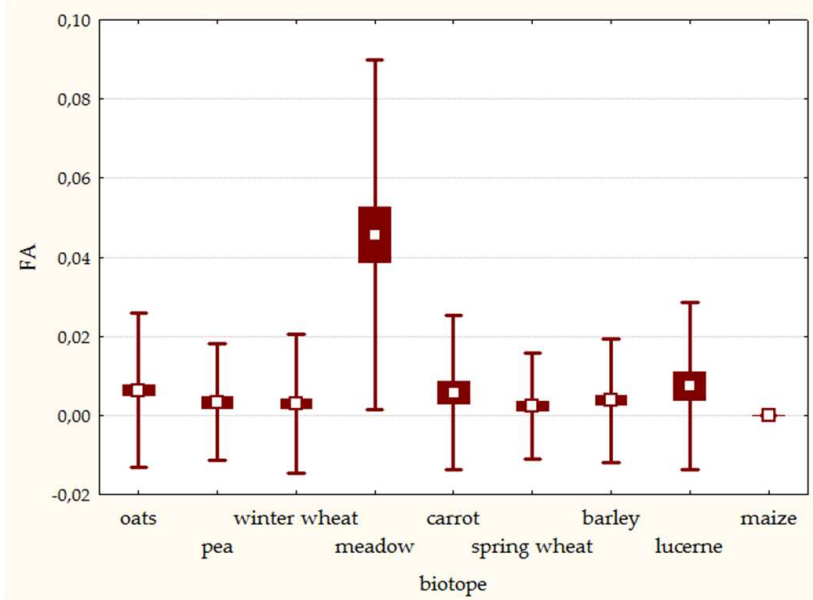

Figure 13. FA in females meristic trait in Poec. cupreus in different biotopes. Mean value (square), mean \pm SE (boxes), mean $\pm \mathrm{SD}$ (whiskers). 


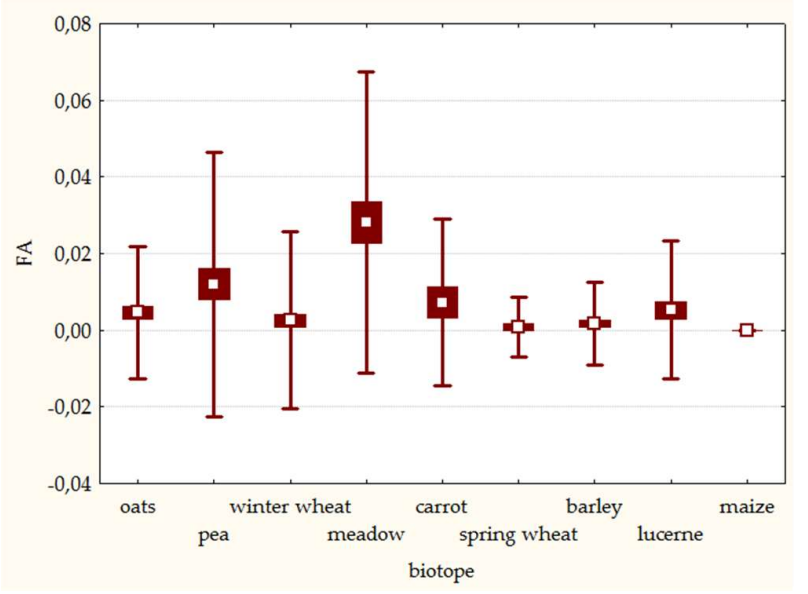

Figure 14. FA in males meristic trait in Poec. cupreus in different biotopes. Mean value (square), mean \pm SE (boxes), mean \pm SD (whiskers).

In our work we used modeling not by chance. Environmental factors are unpredictable and occur at random in time and space. The course of the weather or disruptive changes in the environment are environmental factors that can affect the FA in insects. In our data set we compiled samples taken in different provinces, in gradient of anthropogenic press and in different year, so that possible random deviations of FA in certain plot of sampling could neutralize each other and the only biotope impact on FA variation could be estimated.

We confirmed hypothesized biotope*species interaction when affecting FA. Every species has its own preferences for humidity, lightness, canopy cover etc.

The fact remains unexplained in negative relation on FA variation in dimensional and meristic traits in C. granulatus and C. cancellatus again: in both species FA levels in dimensional and meristic trait changed in opposite in relation to biotope type directions. And exactly in those species FA in males was higher than in females. In other studied species males responded to biotope characters about the same as females. So unlike the previous studies [10] we did not find sex*biotope interaction in effect to FA in most cases. Perhaps it can be explained by species-level peculiarities of C. granulatus and C. cancellatus. Both are large forest zoophagous and very rarely are met in open habitats and arable landscapes. These uncommon habitats affect negatively those species including developmental stability and lead to high FA values in lawns and raspberry (Fig. 3,4). $P$. oblongopunctatus is the forest species too. And the discussed negative relation on FA variation in dimensional and meristic traits was revealed in it too, though it is relatively small species.

Unlike discussed above forest species, P. melanarius and Ps. rufipes are ubiquists. They feel equally good both in forest and open biotopes. Perhaps due to their "generalists" characters they did not show differences in male/female response to habitats and multidirectional variation of FA in dimensional and meristic traits (Fig. 8,10).

Separate part of discussion should be devoted to Poec. cupreus because its data set was based on arable land habitats. The latter are characterized by soil and pesticide treatments. Crops provide different environmental conditions and food availability which are two of the most important factors influencing carabid beetle distribution [드-28 ]. In addition, crops also differ in the intensity and timing of management practices, such as soil tillage and harvesting, which are determined by crop successions [29]. Agricultural practices have been shown to influence carabid beetle abundance 
either directly, through mortality and emigration, or indirectly, by affecting local microhabitat conditions $[\underline{18}-20,22]$. Accordingly, studies which investigated the effect of crop management practices on the species composition of carabid communities concluded that the crop type was one of the most influential factors [ $\underline{30}-\underline{32}]$. Taking into account all these factors it was not surprising that FA in P. cupreus dimensional and meristic traits varied greatly in different crops. But some conclusions should be done: the lowest FA in spring wheat was observed (as in C. cancellatus, by the way). The low soil disturbance in that crop can lead to the more stable development of beetles, especially their larva. The second feature was the highest FA in both traits and in both sexes in the meadows. That fact can be related to the natural conditions in meadows, where P. cupreus has its natural enemies and competitors, unlike arable lands where it is the eudominant. And the last feature of FA variation in this species: in tall crops (lucerne, maize) FA standard error were significantly higher, suggesting that those kinds of crops affected beetles selectively.

So we confirmed three out of four hypothesized suggestions: factor "biotope" and its interaction with factor "species" affected FA in ground beetles the latter being higher in uncommon biotopes. FA were higher in males than in females in a small number of cases.

\section{Conclusions}

The use of FA as the bioindicator of environmental stress is complicated by the fact that information on the basic ecology of individual species is relatively scant and contradictory for even the most common species. Revealed habitat impact on FA values in ground beetles demands the detailed understanding of species distribution among habitats at the different life stages. The latter can provide insights into their ecological requirements, possibly allowing to design ecological strategies of management through environmental engineering.

Author Contributions: Conceptualization, R.A.S.,N.I.E. and N.L.U.; methodology, R.A.S. and A.A.S.; software, A.A.S.; validation, R.R.Shagidullin; formal analysis, T.A.G. and N.L.U.; investigation, I.A.S., A.L.A. and I.G.V.; resources, I.A.S., A.L.A., N.I.E. and I.G.V; data curation, R.R.S.; writing-original draft preparation, R.A.S. and A.L.A.; writing-review and editing, R.A.S. N.I.E. and T.A.G.; visualization, T.A.G.; supervision, R.A.S. N.I.E. and A.A.S.; project administration, R.R.S.; funding acquisition, N.L.U.

Funding: This research received no external funding.

Acknowledgments: We thank the staff of Mariy El and Kemerovo State Universities for the help in beetles sampling. We thank the staff of Laboratory of Biomonitoring of Research Institute for Problems of Ecology and Mineral Wealth Use of Tatarstan Academy of Sciences for beetles sampling in Tatarstan Republic and the assistance in their measurements.

Conflicts of Interest: The authors declare no conflict of interest.

\section{References}

1. Peters, R. H. The ecological implications of body size; Publisher: Cambridge University Press, Cambridge, UK, 1983; pp. 1-329.

2. Martin, A. P.; Palumbi S. R.Body size, metabolic rate, generation time, and the molecular clock. Proc. Natl Acad.Sci. USA1993, 90, 4087-4091.

3. Silva, M.; DowningJ. A.The allometric scaling of density and body mass: a nonlinear relationship for terrestrial mammals. Am. Nat.1995, 145, 704-727.

4. Trotta, V.; Calboli, C.; Garoia, F.; Grifoni, D.; Cavicchi, S. Fluctuating asymmetry as a measure of ecological stress in Drosophila melanogaster (Diptera: Drosophilidae). Eur. J. Entomol. 2005, $102,195-200$.

5. Schmeller, D.S.; Dolek, M.; Geyer, A.; Settele, J.; Brandl, R. The effect of conservation efforts on morphological asymmetry in a butterfly population. J. Nat. Conserv.2011, 19, 161-165. 
6. Speight, M.C.D.Criteria for the selection of insects to be used as bio-indicators in nature conservation research. Proceedings of the 3rd European Congress of Entomology. Amsterdam; ed. by H.H.W. Velthuis;Nederlandse Entomologische Vereniging, Haarlem, the Netherlands 1986, pp. 486-489.

7. Labrie, G.; Prince, C.; Bergeron, J.-M. Abundance and developmental stability of Pterostichus melanarius (Coleoptera: Carabidae) in organic and integrated pest management orchards of Québec, Canada. Environ. Entomol.2003, 32, 123-132.

8. Rainio, J.; Niemel€a, J. Ground beetles (Coleoptera: Carabidae) as bioindicators. Biodiversity and Conservation2003, 12, 487-506.

9. Elek, Z.; Lövei, G.L.; Bátki, M. No increase in fluctuating asymmetry in ground beetles (Carabidae) as urbanisation progresses. Community Ecol.2014, 15, 131-138.

10. Sukhodolskaya, R.; Saveliev, A.; Mukhametnabiev, T.; and Eremeeva, N. Fluctuating Asymmetry in Ground Beetles (Coleoptera, Carabidae) and Conditions of Its Manifestation. Symmetry2019, 11, 1475.DOI:10.3390/sym11121475

11. Sukhodolskaya, R. Variation in Body Size and Body Shape in Ground Beetle Pterostichus melanarius Ill. (Coleoptera, Carabidae).Journal of Agri-Food and Applied Sciences.Available online at jaas.blue-ap.org (2014 JAAS Journal. 31 July 2014, 2(7), 196-205. E-ISSN: 2311-6730.

12. Sukhodolskaya, R.A.; Avtaeva, T.A.; Brigadirenko, V.V.; Antsiferov, A.L.; Kushalieva, Sh.A. Tendencies of Poecilus cupreus Morphometric Alteration Depending on Habitation Region. Advances in Engineering Research2018, 177, 10-15.

13. Luff, M.L. The morphology and microclimate of Dactylis glomerata tussocks. J. Ecol.1965, 53, 771-787.

14. Luff, M.L. Cold hardiness of some beetles living in Grass tussocks. Entomol. Exp. Appl.1966, 9, 191-199.

15. Wallin, H.; Chiverton, B.S.; Ekbom, B.S.; Borg, A. Diet,fecundity and egg size in some polyphagous predatorycarabid beetles. Entomol. Exp. Appl.1992, 65, 129-140.

16. Dennis, P.; Thomas, M.B, Sotherton, N.W. Structural features of field boundaries which influence the overwintering densities of beneficial arthropod predators. J. Appl. Ecol.1994, 31, 361-370.

17. Bommarco, R. Feeding, reproduction and community impact of a predatory carabid in two agricultural habitats. Oikos.1999, 87, 89-99.

18. Kromp, B. Carabid beetles in sustainable agriculture: a review on pest control efficacy: cultivation impacts and enhancement. Agric. Ecosyst. Environ. 1999, 74, 187-228.

19. Cole, L.J.; McCracken, D.I.; Dennis, P.; Downie, I.S.; Griffin, A.L.; Foster, G.N.; Murphy, K.J.; Waterhouse, T.Relationships between agricultural management and ecological groups of ground beetles (Coleoptera Carabidae) on Scottish farmland. Agric. Ecosyst. Environ.2002, 93, 323-336.

20. Thorbek, P.; Bilde, T. Reduced numbers of generalist arthropod predators after crop management. J. Appl. Ecol.2004, 41, 526-538.

21. Pywell, R.F.; James, K.L, Herbert, I., Meek, W.R., Carvell, C., Bell, D., Sparks, T.H. Determinants of overwintering habitat quality for beetles and spiders on arable farmland. Biol. Conserv. 2005, 123, 79-90

22. Hatten, T.D.; Bosque-Perez, N.A.; Labonte, J.R.; Guy, S.O.; Eigenbrode, S.D. Effects of tillage on the activity density and biological diversity of carabid beetles in spring and winter crops. Environ. Entomol.2007, 36, 356-368.

23. Korenko, S., Pekar S. Is there intraguild predation between winter-active spiders (Araneae) on apple tree bark? Biol. Control2010, 54, 206-212.

24. Haschek, C.; Drapela, T.; Schuller, N.; Fiedler,K.; Frank, T.Carabid beetle condition, reproduction and density in winter oilseed rape affected by field and landscape parameters.J. of Appl. Entomol.2012,136, 665-674

25. Knapp,M.; Saska, P.The effects of habitat, density, gender and duration on overwintering success in Bembidion lampros (Coleoptera: Carabidae). J. of Appl. Entomol.2012,136, 225-233 
26. Luff, M.L. Biology of polyphagous ground beetles in agriculture. Agric. Zool. Rev. 1987, 2, 237-278.

27. Holland, J.M. Carabid beetles: their ecology, survival and use in agroecosystemsIn book: The Agroecology of Carabid Beetles. In: The Agroecology of Carabid Beetles; Holland, J.M. (Ed.); Publisher: Intercept Limited, Andover, UK,2002; pp. 1-40.

28. Thomas, C.F.G.; Holland, J.M.; Brown, N.J. The spatial distribution of carabid beetles in agricultural landscapes. In: The Agroecology of Carabid Beetles;Holland, J.M. (Ed.); Publisher: Intercept Limited, Andover, UK,2002; pp. 305-344.

29. Joannon, A.; Bro, E.; Thenail, C.; Baudry, J.Crop patterns and habitat preferences of the grey partridge farmland bird. Agron. Sustain. Dev.2008, 28, 379-387.

30. Booij, C.J.H.; Noorlander, J.Farming systems and insect predators. Agric. Ecosyst. Environ.1992, 40, 125-135.

31. Weibull, A.C.; Östman, Ö.Species composition in agroecosystems: the effect of landscape habitat, and farm management. Basic Appl. Ecol.2003, 4, 349-361.

32. Eyre, M.D.; Luff, M.L.; Leifert, C. Crop, field boundary, productivity and disturbance influences on ground beetles (Coleoptera: Carabidae) in the agroecosystem. Agric. Ecosyst. Environ. 2013, $165,60-67$. 